\title{
Stem tangential strain on the tension wood side of Fagus crenata saplings
}

\begin{abstract}
The tangential strain on the inner bark surface of Fagus crenata sapling stems was continuously measured using strain gauges. The total strain increased daily, increasing at night and decreasing during the day. When tension wood was induced by artificial inclination, the strain increased more on the upper side than on the lower side; and the increment in the strain at night was larger on the upper side than on the lower. The change in tangential strain on the inner bark surface arose from changes in the water content and the volume of differentiating cells. Differentiating tension wood fibers appear to contain more water and to expand more at night than differentiating normal wood fibers. We can determine whether tension wood is formed from the tangential strain during growth.
\end{abstract}

Key words Fagus crenata Blume - Tension wood · Hydraulic growth $\cdot$ Stem tangential strain $\cdot$ Gelatinous fiber

\section{Introduction}

The tangential strain on the inner bark surface of tree stems increases daily due to xylem thickening with repeated diurnal changes, increasing at night and decreasing during the daytime. The diurnal change in the strain is primarily due to volumetric changes in differentiating cells and phloem cells; it is not due to volumetric change in the xylem. ${ }^{1}$ The diurnal change in the strain correlates with changes in the leaf and xylem water potentials. ${ }^{2-5}$ At night, when the strain increases, differentiating cells are turgid because they contain

M. Yoshida $(\bowtie) \cdot$ M. Ikawa $\cdot$ K. Kaneda $\cdot$ T. Okuyama Laboratory of Bio-material Physics, Graduate School of

Bioagricultural Sciences, Nagoya University, Nagoya 464-8601, Japan Tel. +81-52-789-4153; Fax +81-52-789-4150

e-mail: yoshida@agr.nagoya-u.ac.jp a lot of water as a consequence of low transpiration, whereas during the day, when the strain decreases, the differentiating cells are desiccated because of high transpiration. The differentiating cells enlarge irreversibly with hydraulic growth, enlarging at night and shrinking during the daytime.

In coniferous saplings, the increment in the tangential strain at night and the decrement during the day are larger on the lower side of an inclined stem, where compression wood is formed, than on the upper side. ${ }^{6}$ This indicates that the volumetric increment and decrement in differentiating compression wood cells are greater than in differentiating cells of normal wood. This phenomenon is thought to be related to high cell-wall extensibility due to the high auxin content and anatomical characteristics of compression wood (e.g., rounded tracheids and intercellular spaces).

In dicotyledonous saplings, does the strain amplitude (i.e., the increment at night and the decrement during the daytime) differ between the normal and tension wood sides? Because cells grow as a consequence of water uptake, a change in the tangential strain in tension wood should be reflected in fewer and smaller vessels and in gelatinous fibers that are more slender than normal fibers. ${ }^{7-10}$ To answer the above question, we investigated the tangential strain on the inner bark surface of inclined beech saplings that formed tension wood on the upper side.

\section{Materials and methods}

Experiments were conducted in 2000 and 2001. During the active growth period the tangential strains on the inner bark surface were measured in 26 Fagus crenata Blume saplings ( 3 or 4 years old; average height $85 \mathrm{~cm}$; average diameter $9 \mathrm{~mm}$ ) grown in pots placed in a field at Nagoya University (Japan). During the measurements the saplings were kept upright for 10 days and then inclined at 30 degrees for 10 days (Fig. 1). A pole was attached to each stem to prevent the stem from sagging from its own weight. After measuring the strains the tissues were observed microscopically. 


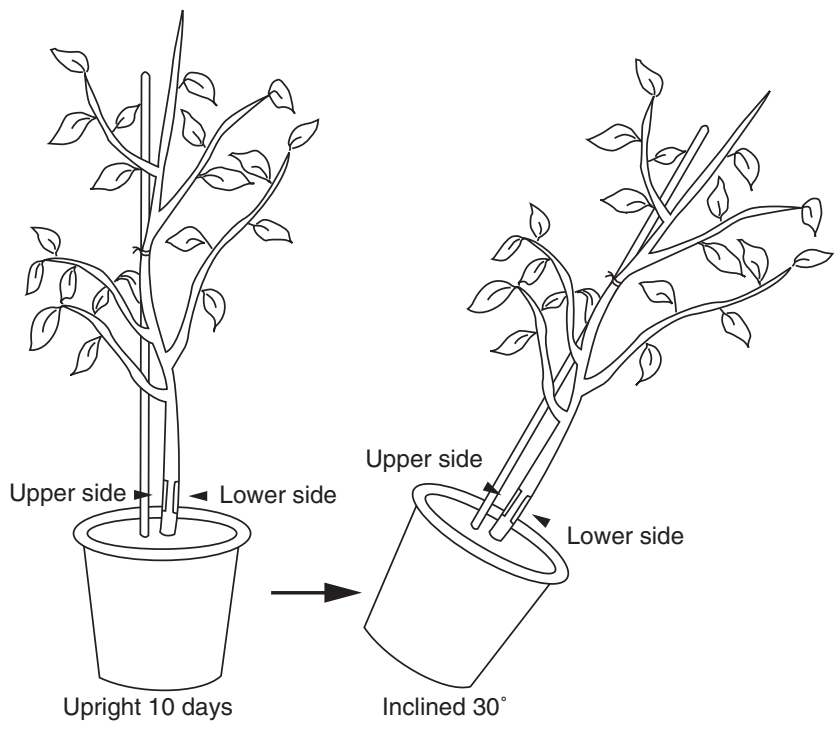

Fig. 1. Procedure used to incline saplings artificially. Arrowheads indicate where strain gauges were glued on the inner bark surface tangentially

Measuring tangential strain on the inner bark

A knife was used to remove 10-mm squares of outer bark from opposite sides of the stem $5 \mathrm{~cm}$ from the ground; these positions became the upper and lower sides when the sapling was inclined (Fig. 1). Strain gauges (2-mm long) were glued tangentially to the smooth surface of the inner bark. To prevent signal drift due to temperature changes, each strain gauge was connected to a strain meter by a three-wire connection. To avoid evaporation and direct irradiation by light, the strain gauge and inner bark were covered with layers of lanolin, a vinyl sheet, and aluminum foil. ${ }^{11}$ Measurements were made at 5-min intervals.

\section{Microscopy}

After measuring the strain, the stem segments where the strain gauges were attached were fixed in 3\% glutaraldehyde at $4^{\circ} \mathrm{C}$, and $15-\mu \mathrm{m}$-thick transverse sections were cut with a sliding microtome. The sections were stained with safranine and fast green and then were observed under an optical microscope. The transverse diameters of the fibers were measured using an image analysis system (Mac Scope; Mitani, Tokyo, Japan).

\section{Results}

\section{Microscopy}

Gelatinous fibers formed in the current layer on the upper side of the inclined stems (Fig. 2). The number of vessels decreased in the region with gelatinous fibers. The transverse diameters of the gelatinous fibers were

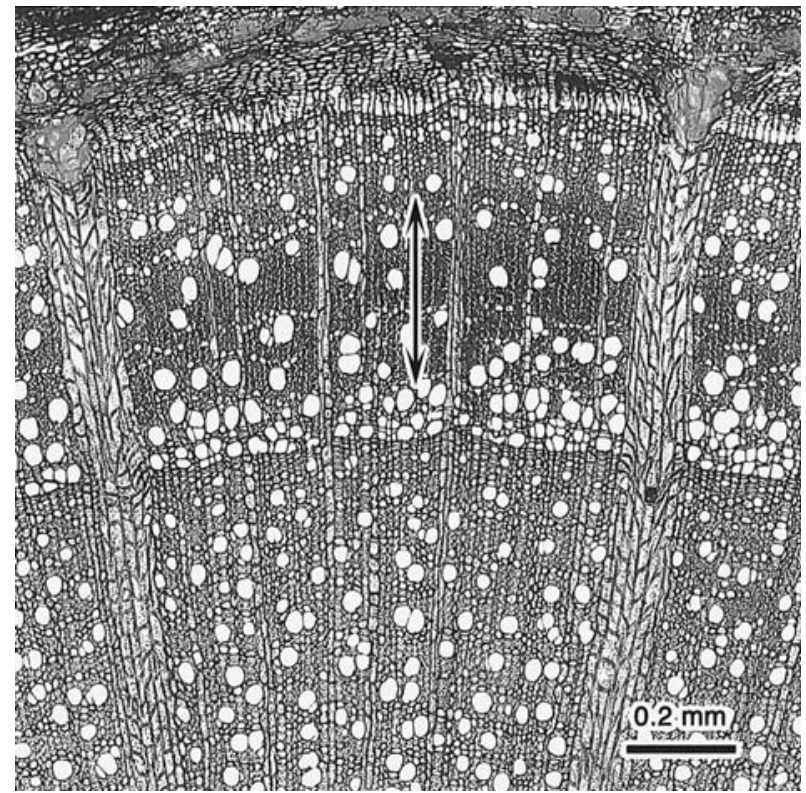

Fig. 2. Transverse section at a strain measuring point on the upper side of a sapling inclined $30^{\circ}$. Double-headed arrow indicates the tension wood region induced by inclination

smaller than those of normal fibers $(8.9 \pm 1.1$ vs. $11.5 \pm$ $1.3 \mu \mathrm{m}, P<0.001)$.

\section{Changes in tangential strain}

Diurnal changes in the tangential strain were observed. The tangential strain increased daily with repeated diurnal changes, increasing at night and decreasing during the daytime on sunny days (Fig. 3). Decreases in the strain were minimal on rainy or cloudy days. When the saplings were upright, the daily increases of the strain were equal on both sides. After the saplings were inclined, the strain on the upper side began to increase markedly.

Amplitude changes in the tangential strain stimulated by inclination

The diurnal increment and decrement in the tangential strain within a 24-h period (i.e., the change in amplitude) was investigated. The diurnal increment was defined as the increment in the strain at night, from its minimum to its maximum (Fig. 3, from arrow 1 to arrow 2). The diurnal decrement was defined as the decrement in the strain during the day, from its maximum to its minimum (Fig. 3, from arrow 2 to arrow 3 ).

Figure $4 \mathrm{~A}$ is a scatter diagram that compares the diurnal increments under upright and inclined conditions in one sapling. Each plot shows the diurnal increments on both the upper and lower sides on the same day. The daily increment differed with sunshine and humidity, but the plots lie on a straight line because the increment was large on the upper side when the increment was large on the lower side. This 
Fig. 3. Change in the tangential strains measured on the inner bark surface of an inclined sapling. The strain reached a minimum during the day (arrows 1,3) and reached a maximum just before dawn (arrow 2)

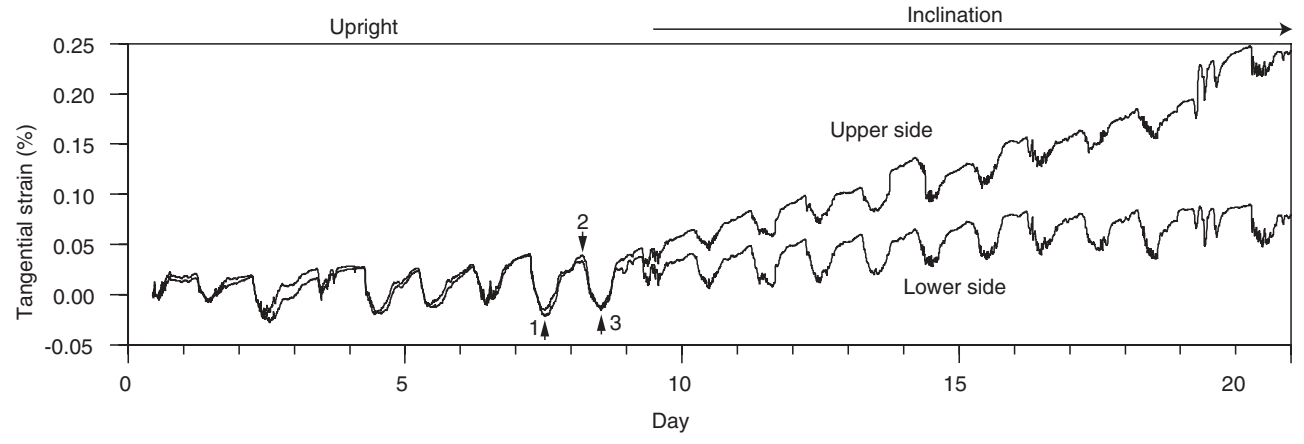

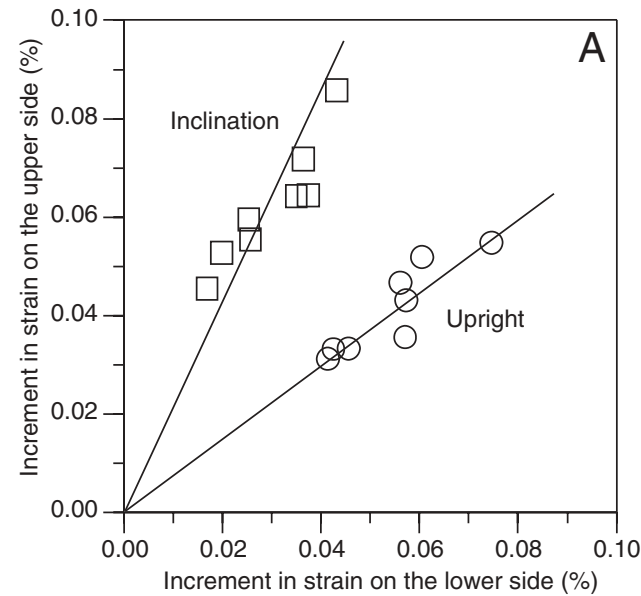

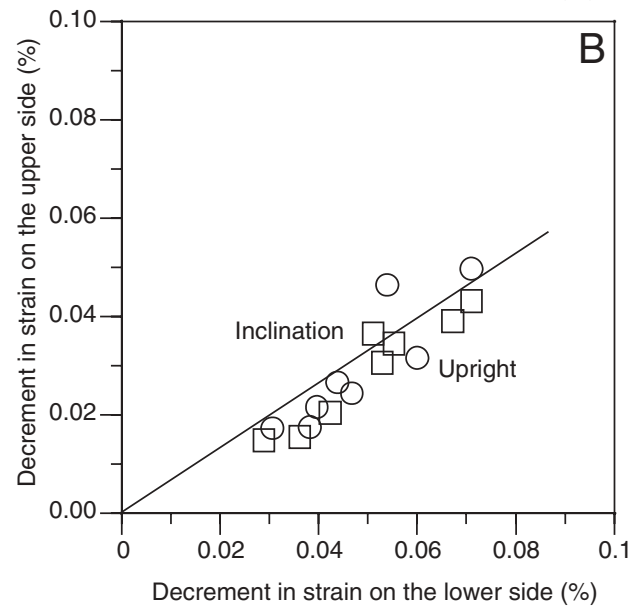

Fig. 4. Diurnal change in amplitude of the tangential strain in the stem. A Increment at night. B Decrement during the day

figure shows that when the stem was inclined the diurnal increments became larger on the upper side of the stem than on the lower side. For example, when the increment on the lower side was $0.04 \%$, the increment on the upper side was $0.03 \%$ under the upright condition and $0.08 \%$ under the inclined condition.

Figure 4B shows the diurnal decrements on the upper and lower sides under both upright and inclined conditions. All the plots lie on a straight line, indicating that the diurnal decrement on the upper side did not become larger when the stem was inclined.
Table 1. Saplings in which the diurnal amplitude of the tangential strain on the upper side changed after inclination compared to the lower side

\begin{tabular}{|c|c|c|c|c|}
\hline \multirow[t]{2}{*}{ Region } & \multicolumn{2}{|c|}{ Increment at night } & \multicolumn{2}{|c|}{ Decrement in daytime } \\
\hline & Larger & No difference & Larger & No difference \\
\hline Tension wood & 15 & 0 & 4 & 11 \\
\hline Normal wood & 3 & 8 & 2 & 9 \\
\hline
\end{tabular}

Significant at the $5 \%$ level

Artificial inclination induced tension wood formation on the upper side of the stem in all 26 saplings. Of these saplings, 15 produced tension wood under the strain gauge, whereas 11 did not. In the 11 saplings, the tangential strains were measured on normal wood, even after inclination. Table 1 summarizes the amplitude changes of the strain after inclination for all saplings. The increments in the strain at night became larger on the upper side than on the lower side in all 15 saplings in which the strain was measured on tension wood after inclination. In these saplings, the decrements in the strain during the day did not differ between the upper and lower sides after inclination. Of the 11 saplings in which the strain was measured on normal wood after inclination, the increment after inclination did not differ in 8 and the decrement after inclination did not differ in 9 .

In 15 saplings in which the strain was measured on tension wood after inclination, the ratios of the strain increment at night on the upper side to the lower side were calculated. The ratios were larger under the inclined condition than under the upright condition $(1.94 \pm 0.13$ vs $1.17 \pm$ $0.10 ; P<0.001)$.

\section{Discussion}

The tangential strain measured on the upper side of the inclined stem exceeded that measured on the lower side. Thickening growth was promoted on the upper side (Fig. 3). Additionally, gelatinous fiber formation and the reduced number of vessels on the upper side in the current growth layer (Fig. 2) demonstrate that the artificial inclination induced tension wood formation on the upper side of the stem. 
In some cases the strain gauges could not detect the strain in the tension wood region induced by the artificial inclination. The strain gauges were glued where we expected tension wood to form, but the tension wood instead formed laterally because the stem was twisted by the weight of its branches. Consequently, the 11 inclined saplings in which no tension wood formed under the strain gauges were used as a control group. As Table 1 shows, when tension wood formed under a strain gauge the increment in the tangential strain at night was larger on the upper side than on the lower side; when tension wood was not formed under the strain gauge, the increment in the strain on the upper side was not larger, even in the inclined stem. Therefore, we conclude that the increment in the tangential strain on the inner bark surface at night is larger on the tension wood side than on the normal wood side.

Three factors are responsible for the larger increment in the strain over differentiating tension wood: many differentiating cells, an excess of water, and high cell wall extensibility. The first factor probably explains the greater number of cambial cells, broader cambial zone, and larger cambial initial cells on the tension wood side. ${ }^{12}$ The activated cambium promotes the growth in thickness, which increases the daily strain (Fig. 3).

The change in the tangential strain on the inner bark surface is induced by changes in the water content and the volume of differentiating cells. ${ }^{13-15}$ The increment in the strain at night was larger on the tension wood side than the normal side, which shows that differentiating tension wood expands at night more than differentiating normal wood as a consequence of the greater volume of water. Gelatinous fibers are longer than normal fibers, ${ }^{7}$ which likely results from water driving cell enlargement.

The increment in tangential strain on the inner bark surface at night was larger on the tension wood side than the normal wood side. Whether tension wood is being formed can be determined from the stem tangential strain during growth.

\section{References}

1. Molz FJ, Klepper B (1973) On the mechanism of waterstress-induced stem deformation. Agron J 65:304-306

2. Sholander PF, Hammel HT, Bradstreet ED, Hemmingsen EA (1965) Sap pressure in vascular plants. Science 148:339-346

3. Lassoie JP (1973) Diurnal fluctuations in a Douglas-fir stem in response to tree water status. For Sci 19:251-255

4. McBurney T, Costigan PA (1984) The relationship between stem diameter and water potentials in stems of young cabbage plants. $J$ Exp Bot 35:1787-1793

5. Ueda M, Shibata E (2001) Diurnal changes in branch diameter as indicator of water status of hinoki cypress Chamaecyparis obtusa. Trees 15:315-318

6. Yoshida M, Yamamoto O, Okuyama T (2000) Strain changes on the inner bark surface of an inclined coniferous sapling producing compression wood. Holzforschung 54:664-668

7. Onaka F (1949) Studies on compression- and tension-wood. Mokuzai Kenkyu (Wood Research Institute, Kyoto University) $1: 1-88$

8. Li Y, Fujita M (1997) Xylem in some dicotyledon inclined artificially. In: Abstracts of the 47th annual meeting of the Japan wood research society (in Japanese). Japan Wood Research Society, Tokyo

9. Yoshida M, Ohta H, Okuyama T (2002) Tensile growth stress and lignin distribution in the cell walls of black locust (Robinia pseudoacacia). J Wood Sci 48:99-105

10. Yoshida M, Ohta H, Yamamoto H, Okuyama T (2002) Tensile growth stress and lignin distribution in the cell walls of yellow poplar, Liriodendron tulipifera Linn. Trees 16:457-464

11. Okuyama T, Yoshida M, Yamamoto H (1995) An estimation of the turgor pressure change as one of the factors of growth stress generation in cell walls: diurnal change of tangential strain of inner bark. Mokuzai Gakkaishi 41:1070-1078

12. Hariharan Y, Krishnamurthy KV (1995) A cytochemical study of cambium and its xylary derivatives on the normal and tension wood sides of the stems of Prosopis juliflora (SW.) DC. Beitr Biol Pflanzen 69:459-472

13. Zweifel R, Item H, Häsler R (2001) Link between diurnal stem radius changes and tree water relations. Tree Physiol 21:869-877

14. Perämäki M, Nikinmaa E, Sevanto S, Ilvesniemi H (2001) Tree stem diameter variations and transpiration in Scots pine: an analysis using a dynamic sap flow model. Tree Physiol 21:889-897

15. Gall R, Landolt W, Schleppi P, Michellod V, Bucher JB (2002) Water content and bark thickness of Norway spruce (Picea abies) stems: phloem water capacitance and xylem sap flow. Tree Physiol 22:613-623 